\title{
Results of large pulmonary homograft implantation for right ventricular outflow tract reconstruction
}

\author{
Simon DANG VAN', Carine Pavy², Guillaume Guimbretière², Julie Boulanger ${ }^{2}$, Pierre \\ Maminirina $^{2}$, Patrice Guerin ${ }^{2}$, and Olivier Baron ${ }^{2}$ \\ ${ }^{1}$ University Hospital Centre Angers \\ ${ }^{2}$ University Hospital Centre Nantes
}

June 17,2020

\begin{abstract}
Background : To evaluate the long-term results of implantation of homogeneous large size of pulmonary homograft (PH) for reconstruction of the right ventricular outflow tract (RVOT). Methods : Between January 2000 and December 2017, 107 patients were implanted with PH for reconstruction of the RVOT. Data were collected retrospectively in this single-center study. PH failure was defined as a peak of gradient $>40 \mathrm{mmHg}$ and/or as a pulmonary regurgitation $>$ grade 2 . Primary endpoint was the re-operation of the RVOT during follow-up. Secondary endpoints were overall survival, occurrence of $\mathrm{PH}$ failure and the rate of re-operation for all cause. Results : Mean age of the recipients was 26.13 ? 13.59 years. Mean size of PH was 23.02 ? 6.87 $\mathrm{mm}$. Re-operation of the RVOT occurred in 8 patients (7.8\%). Time before re-operation was 2.74 years (Interquartile Range: 6.41). Freedom from re-operation for RVOT at 5 and 10 years was respectively $95.7 \%$ and $90.0 \%$. Overall survival at 10 years was $95.2 \%$. PH failure occurred in 13 patients (12.0\%). Mean time before PH failure was 5.00 ? 4.35 years. Freedom from PH failure at 10 years was $81.6 \%$. Re-operation for PH failure occurred in 4 patients (3.9\%). Concomitant tricuspid valve surgery $(\mathrm{p}=0.037)$, initial pulmonary stenosis $(\mathrm{p}=0.04)$, recipient of $\mathrm{PH}<16$ years old $(\mathrm{p}=0.043)$ were risk factors of late reoperation in univariate analysis. Multivariate analysis showed no independent risk factor of late reoperation. Conclusions : Implantation of large PH for RVOT reconstruction provides excellent mid-term results in terms of re-operation.
\end{abstract}

\section{Results of large pulmonary homograft implantation for right ventricular outflow tract recon- struction}

\section{Pulmonary homograft as right outflow tract}

Simon Dang Van ${ }^{1}$, MD, CarinePavy ${ }^{1}$, MD, GuillaumeGuimbretière ${ }^{1}$, MD, JulieBoulanger ${ }^{1}$, MD, PierreMaminirina $^{1}$, MD, PatriceGuerin ${ }^{1}, \mathrm{MD}, \mathrm{PhD}$, OlivierBaron ${ }^{1}, \mathrm{MD}, \mathrm{PhD}$

${ }^{1}$ Department of Pediatric and Congenital Cardiac Surgery, University Hospital of Nantes, France

Corresponding author:

Dr Simon DANG VAN, MD.

Service de Chirurgie Thoracique et Cardiovasculaire

Centre Hospitalier Universitaire d'Angers

4 rue Larrey, 49933 Angers Cedex 09, France

Tel: $+33(0) 24135.45 .73$

Fax: +33 (0)2 41355280 
E-mail:Simon.DangVan@chu-angers.fr

Word count : $\mathbf{4 1 6 2}$

Acknowledgment: none

Conflict of interest: none

Funding: none

Abstract :

Background :

To evaluate the long-term results of implantation of homogeneous large size of pulmonary homograft (PH) for reconstruction of the right ventricular outflow tract (RVOT).

\section{Methods :}

Between January 2000 and December 2017, 107 patients were implanted with PH for reconstruction of the RVOT. Data were collected retrospectively in this single-center study. PH failure was defined as a peak of gradient $>40 \mathrm{mmHg}$ and/or as a pulmonary regurgitation $>$ grade 2 . Primary endpoint was the re-operation of the RVOT during follow-up. Secondary endpoints were overall survival, occurrence of PH failure and the rate of re-operation for all cause.

Results :

Mean age of the recipients was $26.13 \pm 13.59$ years. Mean size of $\mathrm{PH}$ was $23.02 \pm 6.87 \mathrm{~mm}$. Re-operation of the RVOT occurred in 8 patients (7.8\%). Time before re-operation was 2.74 years (Interquartile Range: 6.41). Freedom from re-operation for RVOT at 5 and 10 years was respectively $95.7 \%$ and $90.0 \%$. Overall survival at 10 years was $95.2 \%$. PH failure occurred in 13 patients (12.0\%). Mean time before $\mathrm{PH}$ failure was $5.00 \pm$ 4.35 years. Freedom from PH failure at 10 years was $81.6 \%$. Re-operation for $\mathrm{PH}$ failure occurred in 4 patients $(3.9 \%)$. Concomitant tricuspid valve surgery $(\mathrm{p}=0.037)$, initial pulmonary stenosis $(\mathrm{p}=0.04)$, recipient of $\mathrm{PH}$ $<16$ years old $(\mathrm{p}=0.043)$ were risk factors of late reoperation in univariate analysis. Multivariate analysis showed no independent risk factor of late reoperation.

\section{Conclusions :}

Implantation of large PH for RVOT reconstruction provides excellent mid-term results in terms of reoperation.

Keywords:

Congenital heart disease, pulmonary homograft, right ventricular outflow tract, reoperation

Introduction :

Congenital heart diseases involving the right ventricular outflow tract (RVOT) such as tetralogy of Fallot (TOF), pulmonary atresia or truncus arteriosus are frequently observed in cardiopediatric pathology and require most of the time a surgical correction during childhood. Different techniques have raised to treat an obstruction of the RVOT: pulmonary enlargement with a patch of pericardium and insertion of a right ventricular-pulmonary artery (RV-PA) conduit for reconstruction of the RVOT. Pulmonary homograft (PH) implantation has become over the past decades the conduit of choice for surgical treatment of a RVOT obstruction [1]. Small size of PH implanted [2,3], blood group incompatibility [4,5], young age of the recipient [6] are reported as risk factors of PH failure. Nonetheless, such results have been described with series of $\mathrm{PH}$ implanted with wide range of homograft sizes, according to the body surface index of the recipients who were most of the time newborns and children. Results of PH implantation for RVOT reconstruction are less known in grown-up congenital heart disease $(\mathrm{GUCH})$ patients, especially those who underwent a primary surgical correction of congenital heart disease during childhood. The aim of this study was to evaluate the 
long term results of the implantation of homogeneous sizes of $\mathrm{PH}$ in a grown-up population of patients with congenital heart disease.

Material and methods:

Patients:

Between January 2000 and December 2017, 232 patients underwent PH implantation for RVOT reconstruction. Only patients who received a PH for isolated RVOT reconstruction for correction of a right side congenital heart disease were included in this single-center retrospective study. Patients who received PH concomitant left ventricular outflow tract (Ross procedure, Ross-Konno Procedure, aortic valve replacement, Bentall or Tirone David procedures) reconstruction were excluded from the analysis. Clinical data and echocardiographic data were retrospectively collected using patient's clinical records and operative reports available in the University Hospital of Nantes during the study period.

Pulmonary homograft (PH):

PH implanted in the University Hospital of Nantes were provided by the European Homograft Bank (EHB) in Brussel (Belgium) [7]. PH were harvested from donors heart or explanted heart during heart transplantation. Morphological and quality assessment of the PH was systematically performed by EHB after harvesting. $\mathrm{PH}$ were incubated with 3 antibiotics (lincomycin, vancomycin andpolymixin B) during 20-48 hours, and cryopreserved at $-150^{\circ} \mathrm{C}$ in a $10 \%$ dimethysulfoxid solution. The maximum period of cryopreservation of the $\mathrm{PH}$ was 5 years. All the cryopreserved $\mathrm{PH}$ was decellularized during the study period. The quality criterions of the EHB respected the European recommendations 2006/17/EC and 2006/86/EC.

\section{Selection of the implanted PH:}

The size of the implanted $\mathrm{PH}$ was determined with the body surface and the recipient age, following the Rowlatt table (range $-2<$ Z-Score $<+2$ ) [8]. PH were systematically oversized when implanted in young patients to provide acceptable hemodynamic performances at the end of growth. There was no patient donor matching in terms of ABO group and Rhesus type.

\section{PH implantation:}

The PH was implanted by full sternotomy. Cardiopulmonary bypass (CPB) was established between standard aortic cannulation and selective venous cannulation of the superior and inferior vena cava. A left ventricle vent was inserted through the right superior pulmonary vein and surgery was performed in normothermia during CPB. PH was implanted under $\mathrm{CPB}$ and beating heart or with aortic cross clamping. Myocardial protection was provided by a warm blood cardioplegia injected every $10 \mathrm{~min}$ in child, every 20 min adult. First time of the surgery was the large resection of the RVOT, with the pulmonary valve and part of the right ventricular infundibulum. The pulmonary infundibulum was calibrated to the $\mathrm{PH}$ size, if necessary

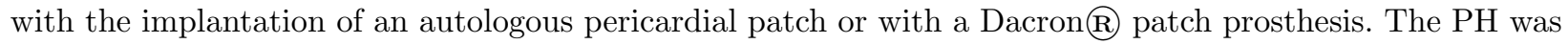
inserted and sutured to the pulmonary infundibulum and the pulmonary artery by continuous suture. More recently, a Dacron $\mathbb{R}$. tube prosthesis has been interposed between the pulmonary infundibulum and the PH if necessary. This maneuver helps to maintain a perfect sphericity of the PH. The distal anastomosis of the $\mathrm{PH}$ was sometimes associated with a pulmonary artery enlargement in case of pulmonary arteries stenosis.

\section{PH failure criterions:}

PH failure occurred when the peak of pulmonary gradient was $>40 \mathrm{mmHg}$, and / or when there was a significant pulmonary regurgitation $>$ grade 2 , as described in previous studies [9].

Primary and secondary endpoints:

Primary endpoint was the re-operation of the RVOT in patients who previously underwent RVOT reconstruction with a PH. Secondary endpoints were the overall survival of patients who underwent RVOT reconstruction with a $\mathrm{PH}$, the rate of re-operation for all causes of the patients implanted with a $\mathrm{PH}$ for RVOT 
and the occurrence of $\mathrm{PH}$ failure (peak of pulmonary gradient $>40 \mathrm{mmHg}$ and/or pulmonary regurgitation $>$ grade 2).

\section{Statistical analysis:}

Statistical analysis were performed with SPSS Statistics@ software (IBM Corporation, New York, USA). Categorial variables were expressed as numbers and percentages. Continuous variables were reported as mean +/- standard deviation (SD) and median with interquartile range (IR) when appropriated. Event-free survival curves were calculated using the Kaplan-Meier method. Univariate analysis was performed by comparing the Kaplan-Meier survival curves using the Log-Rank test to identify risk factors of late re-operation of the PH. Multivariate analysis was performed to identify independent risk factors of late re-operation of the $\mathrm{PH}$, using a Cox regression model. $\mathrm{P}$ value $<0.05$ was retained for statistical significance.

\section{Results:}

Between January 2000 and December 2017, 107 had PH implantation for RVOT reconstruction. Patient's baseline characteristics are summarized in table 1. Mean age of the recipients was $26.13 \pm 13.59$ years. Most of recipient blood types were O-type and A-type (38.3\% and 43.9\%), and Rhesus positive for 91 patients $(85.0 \%)$. The most common primary congenital heart disease was the Tetralogy of Fallot (TOF) (69 patients, 64.5\%). Redo surgery was performed in 101 patients (94.4\%). Primary surgery was performed during childhood and growth either to correct a congenital heart disease (surgical correction of Tetralogy of Fallot, pulmonary atresia, truncus arteriosus, Rastelli operation, RV-PA conduit implantation, arterial switch, REV technique, surgical closure of a septal or atrial septal defect, surgical pulmonary valvuloplasty), or to perform palliative techniques (Blalock-Taussig, central shunt). Some primary congenital heart diseases were associated at initial diagnosis (table 1): 4 patients had transposition of the great arteries (TGA) + ventricular septal defect (VSD) + pulmonary stenosis (PS), 1 patient had TGA + PS, 1 patient with Ebstein disease + PS, 4 patients had VSD + PS, 1 patient had a double outlet right ventricle + pulmonary stenosis, 1 patient had TOF + agenesia of the pulmonary valve, 2 patients had TGA + VSD. Mean age of the donors was $48.78 \pm 11.29$ years. $\mathrm{ABO}$ and Rhesus compatibility between recipient and donors was observed in 30 implantations of $\mathrm{PH}(28.0 \%)$. Isolated ABO compatibility and isolated Rhesus compatibility were respectively observed in $41(38.3 \%)$ and $80(74.8 \%) \mathrm{PH}$ implantations. Mean size of the implanted PH was $23.02 \pm 6.87 \mathrm{~mm}$.

Operative characteristics are summarized in table 2. Indications for PH implantation were: pulmonary regurgitation (PR) (68.2\%), pulmonary stenosis (PS) (25.2\%), pulmonary endocarditis (5.6\%) and changing $\mathrm{PH}$ during other cardiac surgery $(0.9 \%)$. Among patients who underwent $\mathrm{PH}$ implantation for pulmonary regurgitation, 59 patients $(80.8 \%)$ had previous surgical correction of a TOF, 4 patients $(5.5 \%)$ had surgical a previous surgical treatment of pulmonary atresia, 1 patient $(1.3 \%)$ had previous surgical correction of TOF + pulmonary agenesia, 7 patients $(9.6 \%)$ had previous surgical treatment of a PS (3 commissuroplasty, 4 RV-PA conduit) and 2 patients (2.7\%) had surgical correction of a double outlet right ventricle. Among patients who had PH implantation for PS, 8 patients (29.6\%) had previous surgical treatment of truncus arteriosus, 5 patients (18.5\%) had surgical correction for TOF, 5 patients $(18.5 \%)$ had surgical treatment of transposition of the great arteries (TGA) + ventricular septal defect + PS, 1 patient (3.7\%) was operated from TGA + VSD, 1 patient (3.7\%) was operated from TGA + PS, 5 patients (18.5\%) had previous surgical treatment of pulmonary atresia, 1 patient $(3.7 \%)$ had surgical correction of aortic stenosis and 1 patient $(3.7 \%)$ was operated from Ebstein disease + PS. Cross-clamping during PH implantation was performed for 89 patients $(83.1 \%)$ and 18 patients $(16.8 \%)$ had no cross-clamping during PH implantation. Multiple concomitant surgical procedures were performed in 43 patients (39.8\%). Concomitant tricuspid valve surgery occurred in 23 (21.5\%) patients (1 tricuspid valve replacement, 22 tricuspid valve repair). Atrial and ventricular surgeries were associated to PH implantation in 11 patients (10.2\%). Of them, 5 patients (4.6\%) had correction of an atrial septal defect (ASD), 2 (1.8\%) patients had correction of VSD, and $2(1.5 \%)$ patients had REV procedure. Surgical enlargement of the pulmonary arteries for pulmonary stenosis was performed in $10(9.3 \%)$ patients. Concerning the overall survival of patients implanted with a $\mathrm{PH}$ (table 3): in-hospital mortality was $4.6 \%$. Five patients died during the early postoperative period. Among these patients, 2 of 
them died from heart failure ( 1 acute pulmonary edema, 1 severe right ventricle dysfunction caused by pulmonary hypertension), 1 died from sudden ventricular fibrillation, 1 died from respiratory failure and 1 died from acute liver failure. No death occurred during long-term follow-up. Mean follow-up interval was $4.68 \pm$ 4.28 years (median (interquartile range): 2.99 years (6.19)). Overall survival during follow-up at 1,5 and 10 years was $95.2 \%$.

Re-operation of RVOT (table 3):

Re-operation of RVOT has been performed in 8 patients (7.8\%). Mean time before re-operation was $5.48 \pm$ 5.04 years. Among these patients, $4(3.9 \%)$ had PH failure. Four patients (3.9\%) were re-operated of RVOT without $\mathrm{PH}$ dysfunction: 1 patient for $\mathrm{PH}$ injury during pace maker implantation and 3 patients for stenosis of the pulmonary artery branches. Re-operation of the RVOT consisted in $\mathrm{PH}$ replacement with an other $\mathrm{PH}$ in 5 patients, percutaneous transcatheter valve implantation in pulmonary position (Edwards Lifesciences Sapien XT?, Irvine, CA, USA) in 2 patients and 1 RV-PA conduit implantation. Surgical enlargement of the branches of the pulmonary arteries was performed in 3 patients who presented stenosis of the pulmonary artery branches. Freedom from re-operation of $\mathrm{PH}$ during follow-up at 1,5 and 10 years was respectively $100 \%, 95.7 \%$ and $90.0 \%$ (Figure 1). Bentall procedures were associated with $\mathrm{PH}$ replacement in 2 patients (1 ascending aorta aneurysm, 1 ascending aorta wound during surgery).

[Insert Figure 1]

PH failure (table 3):

$\mathrm{PH}$ failure occurred in 12 patients (11.7\%) during follow-up. Mean time before PH failure was $5.00+-4.35$ years. PH failure resulted in $\mathrm{PH}$ stenosis in 11 patients $(10.1 \%)$ and 2 patients (1.8\%) presented $\mathrm{PH}$ disease (significant PS and PR $>$ grade 2). Among these patients, 4 (3.9\%) were re-operated of the $\mathrm{PH}$ and the 8 others patients $(7.7 \%)$ who presented PH failure were not re-operated because they did not present criteria for re-intervention according to the European Guidelines [10]. Freedom from PH failure at 1, 5 and 10 years was respectively $100 \%, 93.4 \%$ and $81.6 \%$ (Figure 2).

[Insert Figure 2]

Risk factors for late reoperation:

Univariate analysis of risk factors of late re-operation is summarized in table 4 . Recipient $<16$ years old $(\mathrm{p}=0.043)$, initial pulmonary stenosis $(\mathrm{p}=0.040)$, concomitant tricuspid surgery during PH implantation $(\mathrm{p}=0.037)$ were identified as significant risk factors for re-operation of the RVOT. Isolated PH failure $(\mathrm{p}=0.223)$, isolated stenosis of the pulmonary branches during follow-up $(\mathrm{p}=0.308)$, ABO-Rhesus compatibility $(\mathrm{p}=0.167)$, TOF $(\mathrm{p}=0.069)$, size of $\mathrm{PH}<22 \mathrm{~mm}(\mathrm{p}=0.205)$ and concomitant pulmonary arteries enlargement during PH implantation $(\mathrm{p}=0.361)$ were not significantly identified as risk factors of late reoperation of the RVOT during follow-up. Multivariate analysis is summarized in table 5. No independent risk factor of late re-operation was significantly identified.

Discussion:

In this present case series, late reoperation of the RVOT for PH failure after PH implantation for RVOT reconstruction is of $3.9 \%$ (4 patients), while late $\mathrm{PH}$ failure occurred in 12 patients (11.2\%). $\mathrm{PH}$ implantation for reconstruction of the RVOT was first reported in 1966 by Fulleret al [11] in a 9 year-old girl presenting pulmonary atresia with VSD. Since then, PH gradually became the conduit of choice for RVOT $[2,12]$, considered as the preferred substitute by many surgeons. However, durability of the PH implanted for RVOT reconstruction has been described in studies of children and young adults, and young age of PH implantation is known to be a determinant of the $\mathrm{PH}$ longevity [6]. In our study, mean age of $\mathrm{PH}$ implantation was higher with a mean age of $26.29+-13.62$ years old and provided implantation of a quiet homogeneous range of $\mathrm{PH}$ sizes $(23.06+-6.85 \mathrm{~mm})$. Therefore, the confounding factor related to the small size of the $\mathrm{PH}$ implanted during childhood and the mismatch induced by the patients growth did not affect the results of our study. 
In a similar way, the need of an extra-anatomic PH implantation in children described by Wells et al [13] as a risk factor of $\mathrm{PH}$ has been avoided by routine anatomic PH implantation in this study population.

Patients who were implanted with PH in this study presented a large spectrum of congenital heart diseases, such as TOF, pulmonary atresia, truncus arteriosus or TGA. Therefore, results could be more representative of the PH performance in a wide range of RVOT reconstruction of different GUCH involving the RVOT. To our knowledge, most of the studies reporting the PH durability in GUCH are performed only with TOF patients [14].

Immunological mechanisms have been previously described as risk factors for accelerated PH failure by Baskett et al [5] in a study of children who were implanted with PH. ABO blood group and human antigenDR were significantly identified as prognosis factors of early dysfunction of the PH. Da Costa et al [12] compared decellularized PH to standard PH implanted in children less than 12 years old and found a lower incidence of structural valve disorder in favor of the decellularized conduit. Decellularization of the $\mathrm{PH}$ may reduce the antigenicity of the implanted tissue. Dekens et al[15] also reported that matching ABO compatibility may improve the $\mathrm{PH}$ durability in $\mathrm{PH}$ more than $22 \mathrm{~mm}$ of diameter, but median age of implanted recipients was 15 years old and this conclusion was obtained in a sub-group univariate analysis. In our study, Rhesus and ABO blood group compatibility matching between the recipient and the donor was obtained in only $28.0 \%$ and was not identified as a risk factor of late re-operation for $\mathrm{PH}$ failure in univariate analysis $(\mathrm{p}=0.167)$, of adults implanted with large sizes of PH. This result supports the fact that a young age of implantation may be a confounding factor, and that immunological mechanisms of PH deterioration are maybe less important in adults than in children implanted.

Re-operation rate of $\mathrm{PH}$ is low in our study ( $7.8 \%$ of the patients implanted with $\mathrm{PH}, 3.9 \%$ for secondary $\mathrm{PH}$ failure) and is quiet similar to other studies [14]. However, the rate of $\mathrm{PH}$ failure during follow-up is higher than the re-operation rate because of non clinical or functional evidence of such PH dysfunction. This result emphasizes that current evaluation by echocardiography and magnetic resonance imaging of the $\mathrm{PH}$ performances has to be more effective and reliable with regard to the clinical status.

Concomitant tricuspid valve surgery was also identified as a risk factor of late re-operation of $\mathrm{PH}(\mathrm{p}=0.037)$ univariate analysis, but not in multivariate analysis $(\mathrm{p}=0.504)$. Indication of tricuspid surgery was mostly moderate to severe tricuspid regurgitation and a great majority of the tricuspid surgery consisted in tricuspid annuloplasty with a prosthesis ring. Shaher et al [16] suggested that initial PR induced right ventricle dilatation and tricuspid regurgitation, resulting in deterioration of the right ventricle function. Meijeret al [17] supposed that the dilatation of the right ventricle may cause homograft PR, and suggested that reconstruction of the ventricular outflow tract should be associated to the $\mathrm{PH}$ implantation to restore a normal volume of the right ventricle.

Two of the 8 patients who were re-operated for PH had implantation of transcatheter bioprosthetic valve Sapien XT? (Edwards Lifesciences, Irvine, CA, USA) in the pulmonary position. Since the first transcatheter pulmonary valve implantation reported by Bonhoefferet al [18], this innovative technique has gradually expanded and became a good alternative to pulmonary valve replacement, with similar short and mid-term results [19]. However, long-term performance of surgical pulmonary valve replacement with bioprothesis is well known [5]. Bell et al [20] found that pulmonary valve replacement with a bioprosthetic valve was more than 8 times at risk of re-operation (Hazard Ratio $=8.34$ ) compared to PH implantation for RVOT reconstruction. These different results may suggest that the conduit of choice for RVOT reconstruction is a PH in the setting of GUCH involving the RVOT, but long-term analysis of transcatheter procedures and improvement of the endovascular technology may change clinical practice.

\section{Study limitations:}

Results of this present study should be considered with regard to the inherent limitations resulting in the design of this retrospective single-center observational analysis of a historical series of selected patients with GUCH. Data collection was not optimal, in terms of clinical and echocardiographic parameters collected during follow-up, without specific protocol of follow-up. Thereby, data were not collected at the same time 
of follow-up, and were not complete because of patients lost from follow-up. Mean time of follow-up is low and longer follow-up is required to draw consistent conclusions from this case series.

Conclusions:

Large sizes of PH implantation for RVOT reconstruction in a grown-up population of congenital heart diseases involving the RVOT, except from the congenital heart diseases involving the left ventricle outflow tract, provide excellent mid-term results in terms of re-operation and $\mathrm{PH}$ failure.

Figures Captions:

Figure 1: freedom from re-operation of $\mathrm{PH}$ during follow-up

PH: pulmonary homograft. No patient underwent surgery during follow-up without PH replacement.

Figure 2: Freedom from PH failure during follow-up

PH: pulmonary homograft

Tables captions:

Table 1: Population baseline characteristics

IR: Interquartile range, PH: pulmonary homograft, SD: standard deviation, TOF: Tetralogy Of Fallot

*: some patients had multiple primary congenital heart diseases

\section{Table 2: operative characteristics}

CABG: coronary artery bypass graft, IR: Interquartile range, SD: standard deviation.

*: 43 patients had concomitant other surgical procedures during pulmonary homograft ( $\mathrm{PH})$ implantation. Some of them underwent more than 2 concomitant procedures associated with $\mathrm{PH}$ implantation. 1 patient had concomitant tricuspid valve surgery and ventricular septal defect closure, 4 patients underwent concomitant tricuspid valve surgery and pulmonary arteries enlargement, and 1 patient underwent concomitant ventricular septal defect closure and pulmonary arteries enlargement.

**: 1 dead patient had no concomitant procedure. 4 other patients dead within 30 days after surgery had concomitant procedure associated with $\mathrm{PH}$ implantation (3 ventricular septal defect closure, 1 tricuspid valve replacement + pulmonary arteries enlargement).

\section{Table 3: clinical data during follow-up}

SD: standard deviation, IR: Interquartile range, PH: pulmonary homograft

*: 1 patient had pulmonary endocarditis, 1 patient presented refractory sepsis in the early postoperative period, without evidence of endocarditis

Table 4: Univariate analysis: risk factors of late re-operation

PH: pulmonary homograft, TOF: tetralogy of Fallot

Table 5: Multivariate analysis: risk factor of late re-operation

CI: confidence interval, PH: pulmonary homograft, PS: pulmonary stenosis, SE: standard error, TOF: Tetralogy Of Fallot,

References:

[1] Kalfa DM, Mace L, Metras D, Kreitmann B. How to choose the best available homograft to recontruct the right ventricular outflow tract. J Thorac Cardiovasc Surg. $2011 ; 142$ :950-53 
[2] Kalfa DM, Loundou A, Nouaille de Gorce Y, Fraisse A, Metras DR Mace L et al . Pulmonary position cryopreserved homograft in non-Ross patients : how to improve the results?. Eur J Cardiothorac Surg. $2012 ; 42(6): 981-7$

[3] Sabate Rotes A, Eidem BW, Connolly HM, Bonnichsen CR, Rosedalh JK, Schaff HV et al . Long-term follow-up after pulmonary valve replacement in repaired tetralogy of Fallot. Am J Cardiol. 2014;114(6):901-8

[4] Forbess JM, Shah AS, St Louis JD, Jaggers JJ, Ungerleider RM. Cryopreserved homografts in the pulmonary position: determinants of durability. Ann Thorac Surg. 2001;71(1):54-9

[5] Baskett RJF, Nanton MA, Warren AE, Ross DB. Human leukocyte antigen-DR and ABO mismatch are associated with accelerated homograft valve failure in children: implication for therapeutic interventions. $\mathrm{J}$ Thorac Cardiovasc Surg. 2003;126:232-9

[6] Therrien J, Provost Y, Merchant N, Williams W, Colman J, Webb Get al . Optimal timing for pulmonary valve replacement in adult after tetralogy of Fallot Repair. Am J Cardiol. 2005 ;95:779-82

[7] Jashari R, Goffin Y, Vanderkelen A, Van Hoeck B, du Verger A, Fan Y et al . European Homograft Bank : Twenty years of cardiovascular tissue banking and collaboration with transplant coordination in Europe. Transplant Proc. $2010 ; 42: 183-9$

[8] Rowlatt UF, Rinoldi HJA, Lev M. The quantitative anatomy of the normal child heart. Pediatr Clin North Am. $1963 ; 10: 499-588$

[9] Zoghbi WA, Enriquez-Sarano M, Foster E, Grayburn PA, Kraft CD, Levine RA et al. Recommendations for evaluation of the severity of native valvular regurgitation with two-dimensional and Doppler echocardiography. J Am Soc Echocardiogr. 2003 ;16(7) :777-802

[10] Baumgarnter H, Bonhoffer P, De Groot NMS, de Haan F, Deanfield JE, Galie N et al . ESC Guidelines for the management of grown-up congenital heart disease (new version 2010). Eur Heart J. 2010;31:2915-57

[11] Fuller DN, Marchand P, Zion MM, Zwi Paul. Homograft replacement of the pulmonary valve. Thorax. 1966;21:337-42

[12] Therrien J, Dore A, Gersony W, Iserin L, Leberthson R, Meijboom F et al. CCS Consensus Conference 2001 update: recommandations for the management of adults with congenital heart disease. Part I. Can J Cardiol. 2001;17(9):940-59

[13] Wells WJ, Arroyo H Jr, Bremner RM, Wood J, Starnes VA. Homograft conduit failure in infants is not dur to somatic outgrowth. J Thorac Cardiovasc Surg. 2002;124;88-96

[14] Troost E, Meyns B, Daenen W, Van de Werf F, Gewilig M, Van Deyk K et al. Homograft survival after Tetralogy of Fallot repair: determinants of accelerated homograft degeneration. Eur Heart J. 2007;28:2503-9

[15] Dekens E, Van Damme Eufra, Jashari R, Van Hoeck B, Francois K, Bove T. Durability of pulmonary homografts for reconstruction of the right ventricular outflow tract: how relevant are donor-related factors? Interac Cardiovasc Surg. 2018;28(4):503-509

[16] Shaher RM, Foster E, Farina M, Spooner E, Sheikh F, Alley R. Right heart reconstruction following repair of tetralogy of Fallot. Ann Thorac Surg. 1983;35:421-6

[17] Meijer FMM, Kies P, Jonbloed MRM, Hazekamp MG, Koolbergen DR, Blom NA et al. Excellent durability of homografts position analysed in a predefined adult group with tetralogy of Fallot. Interact Cardiovasc Surg. 2019;128(2):279-83

[18] Bonhoeffer P, Boudjemline Y, Saliba Z, Merckx J, Aggoun Y, Bonnet D et al. Percutaneous replacement of pulmonary valve in a right-ventricle to pulmonary-artery prosthetic conduit with valve dysfunction. Lancet. 2000;356:1403-5 
[19] Caughron H, Kim D, Kamioka N, Lerakis S, Yousef A, Maini Aet al . Repeat pulmonary valve replacement: similar intermediate-term outcomes with surgical and transcatheter procedures. JACC Cardiovasc Interv. 2018;11(24):2495-2503

[20] Bell D, Prabhu S, Betts KS, Chen Y, Radford D, Whight Cet al . Long-term performance of homografts versus stented bioprosthetic valves in the pulmonary position in patients aged 10-20 years. Eur J Cardiothorac Surg. 2018;54(5):946-952






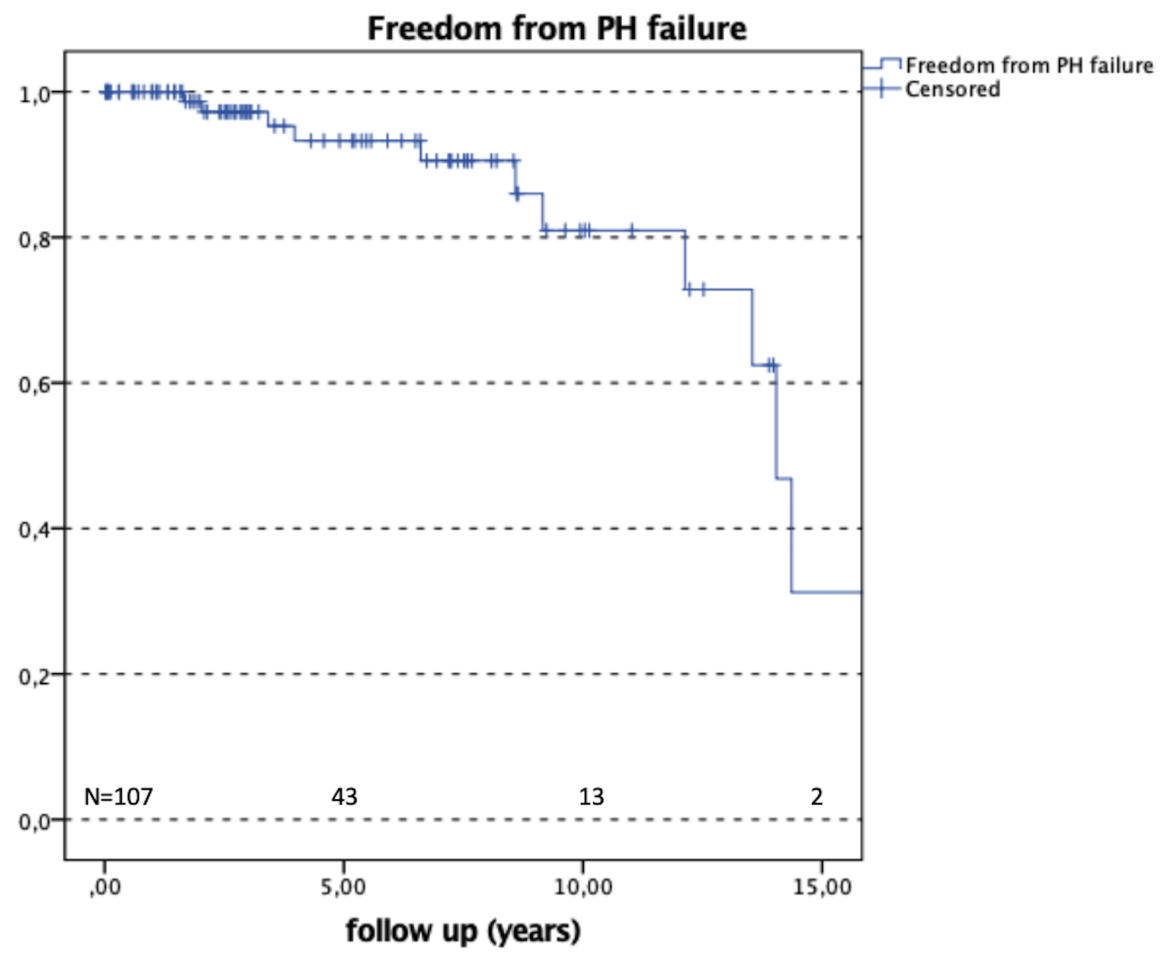

\section{Hosted file}

Table 1 HomoGr.docx available at https://authorea.com/users/334345/articles/460336results-of-large-pulmonary-homograft-implantation-for-right-ventricular-outflow-tractreconstruction

\section{Hosted file}

Table 2 HomoGr.docx available at https://authorea.com/users/334345/articles/460336results-of-large-pulmonary-homograft-implantation-for-right-ventricular-outflow-tractreconstruction

\section{Hosted file}

Table 3 HomoGr.docx available at https://authorea.com/users/334345/articles/460336results-of-large-pulmonary-homograft-implantation-for-right-ventricular-outflow-tractreconstruction

\section{Hosted file}

Table 4 HomoGr.docx available at https://authorea.com/users/334345/articles/460336results-of-large-pulmonary-homograft-implantation-for-right-ventricular-outflow-tractreconstruction

\section{Hosted file}

Table 5 HomoGr.docx available at https://authorea.com/users/334345/articles/460336results-of-large-pulmonary-homograft-implantation-for-right-ventricular-outflow-tractreconstruction 